\title{
ERRATUM
}

\section{Links between atmospheric carbon dioxide, the land carbon reservoir and climate over the past millennium}

\author{
Thomas K. Bauska, Fortunat Joos, Alan C. Mix, Raphael Roth, Jinho Ahn and Edward J. Brook
}

Nature Geoscience 8, 383-387 (2015); published online 27 April 2015; corrected after print 10 June 2015.

In the print and PDF versions of this Letter originally published, the last sentence of the paragraph concerning the double-deconvolution technique should have read: "The data therefore probably rule out a net decrease in organic land carbon stocks between 755 and 1850 CE." In addition, a paper by Schuur et al. was not included in the reference list, and should have been cited as ref. 29 in the following sentence: "Permafrost carbon is also a plausible source of $\mathrm{CO}_{2}$ to the atmosphere during intervals of elevated Arctic temperature ${ }^{29}$, but would require re-expansion of permafrost into previously active soils during cold intervals to act as a sink for $\mathrm{CO}_{2}$." The remaining references have been renumbered to accommodate this addition. These errors have been corrected in the PDF version.

29. Schuur, E. A. G. et al. Climate change and the permafrost carbon feedback. Nature 520, 171-179 (2015). 